\title{
Identification of high permeability channels along horizontal wellbore in heterogeneous reservoir with bottom water
}

\author{
Qiang Zheng $\cdot$ Huiqing Liu $\cdot$ Bo Zhang \\ Nan Li $\cdot$ Fang Li
}

Received: 2 May 2013/Accepted: 28 August 2013/Published online: 8 September 2013

(c) The Author(s) 2013. This article is published with open access at Springerlink.com

\begin{abstract}
Reservoir heterogeneity is one of the main barriers that affect reservoir developing efficiently in the presence of a strong aquifer support. To identify high permeability channels, a coupled model of two phase flow in the formation and variable mass flow in the horizontal wellbore has been built in this paper. Keep the average vertical permeability and the permeability variation coefficient constant, change the distribution of vertical permeability, on the basis of which we can get different relations between cumulative watercut and oil recovery. The study shows that if there is a high permeability channel along the wellbore, a line segment and an inflexion will appear on the curve of cumulative watercut and oil recovery in semi-log coordinate when oil recovery reaches some value. The closer the distance between the high permeability channel and the heel is, the earlier the inflexion and the line segment will appear. At last, the actual curve is compared with the theoretical ones in the oil recovery when the inflexion and the line segment appear, by means of which the high permeability channel could be identified. The result
\end{abstract}

Q. Zheng $(\bowtie) \cdot$ N. Li

CNOOC Research Institute, 100027 Beijing, China

e-mail: zqcup2010@126.com

H. Liu

Key Laboratory for Petroleum Engineering of the Ministry of Education, China University of Petroleum, 102249 Beijing, China

\section{B. Zhang}

Geological Science Research Institute of Shengli Oilfield, SINOPEC, 257015 Dongying, China

F. Li

College of Geophysics and Information Engineering, China

University of Petroleum, Beijing 102249, China calculated through the method is similar to the well log interpretation, and the method can be popularized.

Keywords Heterogeneity - Reservoir with bottom water . Horizontal wellbore pressure drop · High permeability channel . Two phase flow Variable mass flow

\section{Introduction}

In the development process of reservoirs with bottom water by horizontal wells, the nonuniform of water breakthrough time along horizontal wellbore is mainly caused by the wellbore pressure drop and the heterogeneity of the reservoir. As the duration of the development, once the bottom water intrudes, it is difficult to identify the breakthrough locations, which makes water plugging be one of the main obstacles of horizontal well technology. Up to now, studies on water plugging are mainly about bottom water coning mechanism (Recham et al. 2000; Wibowo et al. 2004; Erdal and Rajagopal 1989), plugging technics (Bond A et al. 1997; Zhou et al. 2011) and plugging agent (Zaitoun et al. 1999; Zhou et al. 2010). However, studies on identification of breakthrough locations are infrequent. At present, the main method of identifying the breakthrough locations is well logging, which is not only very expensive, but also difficult to operate ( $\mathrm{Li}$ et al. 2005). Therefore, an economic and effective method of identifying the breakthrough locations is very helpful to the popularity of horizontal well technology. Water breakthrough along horizontal wellbore in reservoirs with bottom water is mainly affected by the distribution of vertical permeability. Bottom water breaks through earlier where high permeability channels exist. Therefore, the crux of water plugging is to plug the high permeability channels. 
A coupled model of two phase flow in the formation and variable mass flow in the horizontal wellbore in reservoirs with bottom water has been built in this paper. Keeping the average vertical permeability and the permeability variation coefficient constant, we can construct different kinds of distributions of vertical permeability along the wellbore by Lorentz curve (Sarabia et al. 1999). Compare the curves of cumulative watercut and oil recovery under different kinds of distributions of vertical permeability along the wellbore with the actual curve to identify the high permeability channels. It is proved that the result is precise and can provide a theoretical basis for putting water plugging of horizontal wells into effect.

\section{Modeling}

\section{Reservoir model}

Assume that there is a horizontal well with a length of $L$ in a heterogeneous reservoir with bottom water and the distance from well to the original oil/water contact is $h$. Figure 1 is the sectional view of the reservoir perpendicular to the horizontal wellbore. Establish a rectangular coordinate system as shown in Fig. 1, with the original oil/water contact as its $x$-axis, and the line through the wellbore and perpendicular to the original oil/water contact as its $z$-axis. Divide the reservoir into $n$ permeability zones along the wellbore to be convenient for solution.

Assume that oil and water are immiscible and incompressible. The two-dimensional and two-phase seepage equation of any point on the section at time $t$ can be written as follows (Liu 1992):

$\phi \frac{\partial S_{w}(t)}{\partial t}+v_{x}(t) \frac{\partial f_{w}\left(S_{w}\right)}{\partial x}+v_{z}(t) \frac{\partial f_{w}\left(S_{w}\right)}{\partial z}=0$

where, $\phi$ is the porosity of the point; $S_{w}(t)$ is the water saturation of the point at time $t ; f_{w}$ is the watercut of the point; $v_{x}(t)$ is the velocity component in direction $x$ of the point at time $t, \mathrm{~m} / \mathrm{d} ; v_{z}(t)$ is the velocity component in direction $z$ of the point at time $t, \mathrm{~m} / \mathrm{d}$.

According to the principle of superposition, the velocity of any point on the section at time $t$ can be written as follows (Liu 1992):

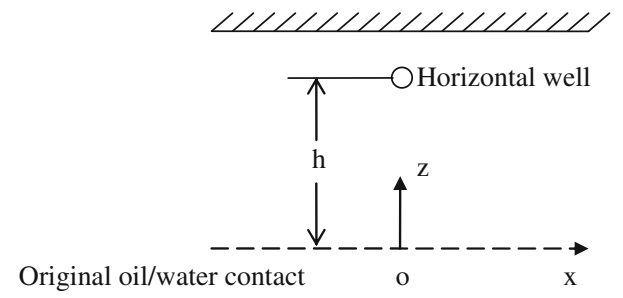

Fig. 1 The section across the horizontal wellbore of the reservoir
$v_{x}(t)=-\frac{Q_{i}(t)}{2 h L_{i}} \frac{\operatorname{sh}(\pi x / 2 h) \sin (\pi z / 2 h)}{c h^{2}(\pi x / 2 h)-\sin ^{2}(\pi z / 2 h)}$

$v_{z}(t)=\frac{Q_{i}(t)}{2 h L_{i}} \frac{\operatorname{ch}(\pi x / 2 h) \cos (\pi z / 2 h)}{\operatorname{ch}^{2}(\pi x / 2 h)-\sin ^{2}(\pi z / 2 h)}$

where, $Q_{i}(t)$ is the liquid production rate in permeability zone $i$ at time $t, \mathrm{~m}^{3} / d ; L_{i}$ is the width of permeability zone $i$, $m ; h$ is the distance from the wellbore to the original oil/ water contact, $m ; x$ is the horizontal coordinate of the point, $m ; z$ is the vertical coordinate of the point, $m$.

As known in equivalent filtrational resistance law (Zhang et al. 2004), flow in every permeability zone can be seen as a combination of two kinds of flow, one is uniflow from the original oil/water contact to the wellbore, and the other one is radial flow from a synthetic supply boundary around wellbore to the wellbore. The productivity equation in permeability zone $i$ at time $t$ can be written as follows (Ehlers and Bluhm 2002):

$Q_{i}(t)=\frac{8.64 \Delta P_{i}(t)}{\frac{\mu_{i}(t)}{L_{i} K_{i} B} h+\frac{\mu_{i}(t)}{2 \pi K_{i} B} \ln \frac{L_{i}}{\pi R_{w}}} \quad(i=1,2, \ldots, n)$

where, $\Delta P_{i}(t)$ is the pressure drop from the original oil/ water contact to the wellbore in permeability zone $i$ at time $t, 10^{-1} \mathrm{MPa} ; \mu_{i}(t)$ is the average viscosity of the fluid in permeability zone $i$ at time $t$, which equals to the weighted mean of the oil viscosity and the water viscosity by water saturation, MPa s $K_{i}$ is the average vertical permeability in

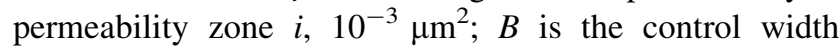
across the horizontal wellbore, $m ; R_{w}$ is the wellbore radius, $m$.

\section{Wellbore model}

As shown in Fig. 2, the wellbore is divided into $n$ infinitesimals which are one-to-one correspondence to the permeability zones in the reservoir.

Assume that fluid in horizontal wellbore is incompressible and flows isothermally. According to the mass conservation law and the momentum conservation law, the wellbore pressure drop equation in infinitesimal $i$ at time $t$ can be written as follows (Liu and Jiang 1998):where, $\rho_{i}(t)$ can be calculated by the following equation:

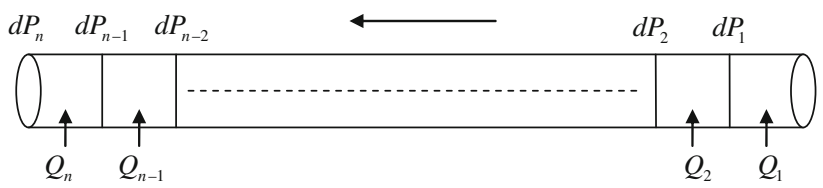

Fig. 2 The horizontal wellbore model diagram 
$d P_{i}(t)=\left\{\begin{array}{lc}10^{-5}\left(\frac{C_{\text {oh }} \rho_{1}(t) L_{1}}{16 \pi^{2} R_{w}^{5}}+\frac{\rho_{1}(t)}{\pi^{2} R_{w}^{4}}\right) Q_{1}^{2}(t) i=1 & i=1 \\ \frac{10^{-5} C_{o h f} \rho_{i}(t) L_{i}}{16 \pi^{2} R_{w}^{5}}\left(2 \sum_{k=1}^{i-1} Q_{k}(t)+Q_{i}(t)\right)^{2}+\frac{10^{-5} \rho_{i}(t) Q_{i}(t)}{\pi^{2} R_{w}^{4}}\left(2 \sum_{k=1}^{i-1} Q_{k}(t)+Q_{i}(t)\right) & i=2,3, \ldots, n\end{array}\right.$

$$
\begin{aligned}
\rho_{i}(t) & =\frac{\sum_{k=1}^{i} Q_{w k}(t)}{\sum_{k=1}^{i} Q_{k}(t)} \rho_{w}+\left(\frac{\sum_{k=1}^{i} Q_{w k}(t)}{\sum_{k=1}^{i} Q_{k}(t)}\right) \rho_{o} \\
& =1,2, \ldots, n) .
\end{aligned}
$$

Water production rate in infinitesimal $i$ at time $t$ can be written as follows:

$$
Q_{w i}(t)=Q_{i}(t) f_{w}\left(S_{w 2 i}(t)\right) \quad(i=1,2, \ldots, n)
$$

where, $d P_{i}(t)$ is the wellbore pressure drop in infinitesimal $i$ at time $t, 10^{-1} \mathrm{MPa} ; f$ is the friction coefficient of the wellbore; $C_{o h}$ is the correction pipe friction factor, which can be obtained by laboratory experiments; $\rho_{i}(t)$ is the average density of the fluid in infinitesimal $i$ at time $t, \mathrm{~kg} /$ $\mathrm{m}^{3} ; \rho_{\mathrm{o}}$ is the oil density, $\mathrm{kg} / \mathrm{m}^{3} ; \rho_{\mathrm{w}}$ is the water density, $\mathrm{kg} /$ $\mathrm{m}^{3} ; Q_{\mathrm{w} i}(t)$ is the water production rate in infinitesimal $i$ at time $t, \mathrm{~m}^{3} / \mathrm{d} ; S_{\mathrm{w} 2 i}(t)$ is the water saturation around the wellbore in permeability zone $i$ at time $t$.

\section{Coupled reservoir-wellbore model}

The pressure drop from the original oil/water contact to the wellbore in permeability zone $i$ at time $t$ and the wellbore pressure drop in infinitesimal $i$ at time $t$ satisfy the following equation:

$$
\Delta P_{i}(t)=\Delta P_{i-1}(t)+d P_{i-1} \quad(i=2,3, \ldots, n) .
$$

Assume that the horizontal well produces with a constant liquid rate of $Q(t)$ during $t \sim t+\Delta t$, we can get the following equation:

$Q(t)=\sum_{i=1}^{n} Q_{i}(t) \quad(i=1,2, \ldots, n)$.

The simultaneous equations above can be solved by iteration method. We can get the distribution of water saturation in the reservoir, liquid rate, pressure, oil rate along wellbore, and watercut in the wellhead at any time.

\section{Analysis of the dynamic characteristic curves}

The distribution of vertical permeability along the wellbore will not affect the dynamic data in the wellhead, if the wellbore pressure drop is ignored. Considering the
Table 1 Base data of the well

\begin{tabular}{ll}
\hline Parameter name & Value \\
\hline Wellbore length $(\mathrm{m})$ & 279 \\
Wellbore radius $(\mathrm{m})$ & 0.075 \\
Distance from bottom water $(\mathrm{m})$ & 40 \\
Water viscosity (mPa s) & 0.75 \\
Oil viscosity (mPa s) & 5 \\
Water density kg m & \\
Oil density $\left(\mathrm{kg} \mathrm{m}^{-3}\right)$ & 1,000 \\
\hline
\end{tabular}

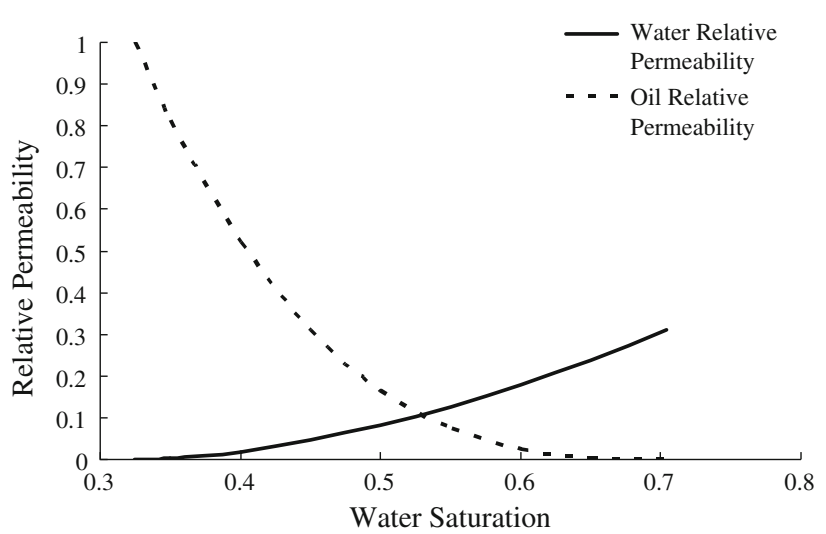

Fig. 3 The oil-water relative permeability curve

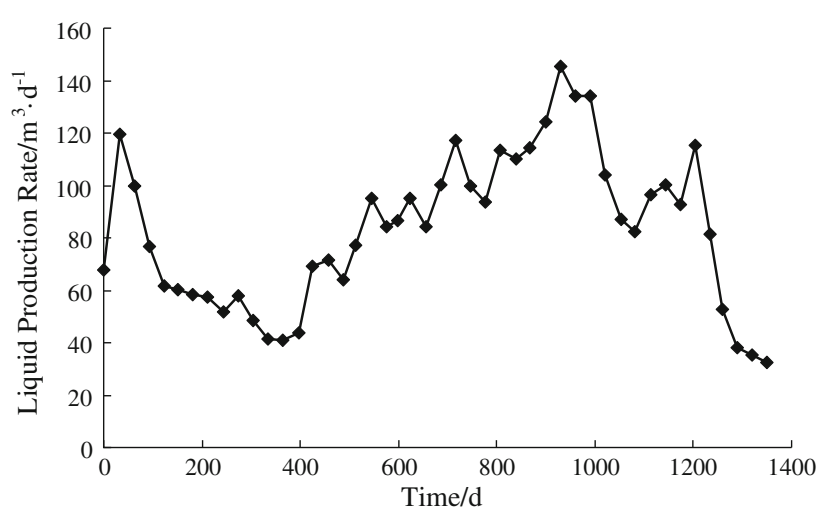

Fig. 4 Liquid production rate curve of the horizontal well 


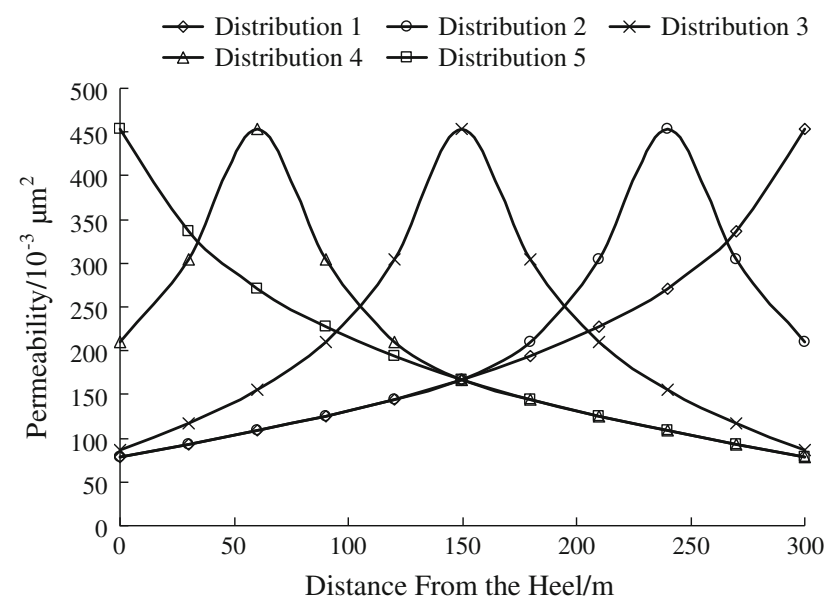

Fig. 5 Five kinds of distributions of vertical permeability along the wellbore

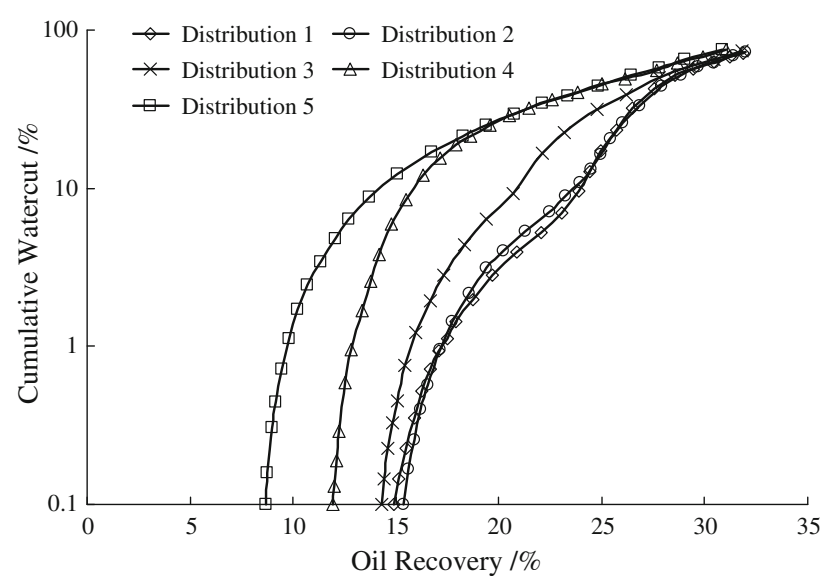

Fig. 6 Curves of cumulative watercut and oil recovery under 5 kinds of distributions of vertical permeability along the wellbore in semi$\log$ coordinate

Table 2 Oil recoveries when the inflexion and the line segment appear under 5 kinds of distributions of vertical permeability along the wellbore

\begin{tabular}{lll}
\hline Distribution & $\begin{array}{l}\text { Oil recovery } \\
\text { (the inflexion } \\
\text { appears) }(\%)\end{array}$ & $\begin{array}{l}\text { Oil recovery } \\
\text { (the line segment } \\
\text { appears) }(\%)\end{array}$ \\
\hline 1 & 22 & 28 \\
2 & 22 & 28 \\
3 & 20 & 27 \\
4 & 14 & 24 \\
5 & - & 20
\end{tabular}

wellbore pressure drop, the influence of the distribution of vertical permeability on producing dynamic data in the wellhead is analyzed with the actual data in TaHe oilfield in China. Keep the average vertical permeability and the permeability variation coefficient along the wellbore constant, change the distribution of vertical permeability, on the basis of which we can get different relations between cumulative watercut and oil recovery. The base data of the well are shown in Table 1. The oil-water relative permeability curve is shown in Fig. 3. Figure 4 shows the liquid production rate during 1,350 days.

Assume that the average vertical permeability along the wellbore is $200 \times 10^{-3} \mu^{2}$, the permeability variation coefficient is 0.3 . Construct 5 kinds of distributions of vertical permeability along the wellbore by the Lorentz curve, which are shown in Fig. 5. The distance from the high permeability channel to the heel of the wellbore is 0 , $L / 4, L / 2,3 L / 4$ and $L$, respectively.

Solve the simultaneous equations with the actual data. Figure 6 shows the curves of cumulative watercut (cumulative water divided by cumulative liquid) and oil recovery under 5 kinds of distributions of vertical permeability along the wellbore in semi-log coordinate.

As shown in Fig. 6, under 5 kinds of distributions of vertical permeability, there will be a line segment on the curve of cumulative watercut and oil recovery when oil recovery reaches some value. Affected by the high permeability channel, an inflexion will appear before the line segment when the distance between the high permeability channel and the heel is greater than 0 . In other words, as the increase of oil recovery, cumulative watercut increases slowly first, then rapidly, and then slowly. A small distance between the high permeability channel and the heel of the wellbore contributes to a fast growth rate of watercut, an early appearance time of the inflexion and the line segment, and a serious effect of the high permeability channel on the watercut. The closer the distance between the high permeability channel and the toe of the wellbore is, the clearer the inflexion will be. When the distance between the high permeability channel and the heel is greater than $3 L / 4$, the influence of the location of the high permeability channel on the curve is little. When the distance between the high permeability channel and the heel is less than $3 L / 4$, the influence of the location of the high permeability channel on the curve becomes greater and greater. When the line segment and inflexion appear, the oil recoveries under 5 kinds of distributions of vertical permeability are shown in Table 2 .

\section{Identification of high permeability channels}

When the line segment and the inflexion appear, oil recoveries will differ with the change of the location of the high permeability channel. According to this character, we can identify the location of the high permeability channel. Figure 7 shows the actual curve of cumulative watercut and oil recovery of the horizontal well in semi-log coordinate. We can see that an inflexion appears when oil 


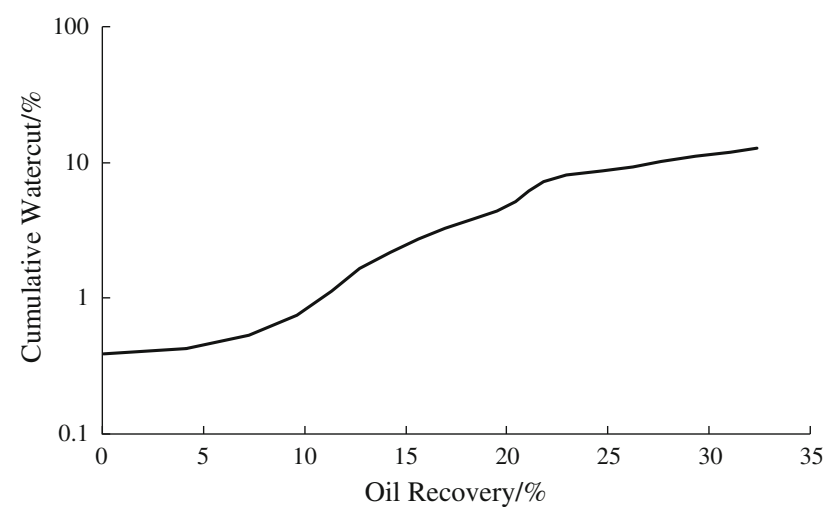

Fig. 7 Actual curve between cumulative watercut and oil recovery of the horizontal well in semi-log coordinate

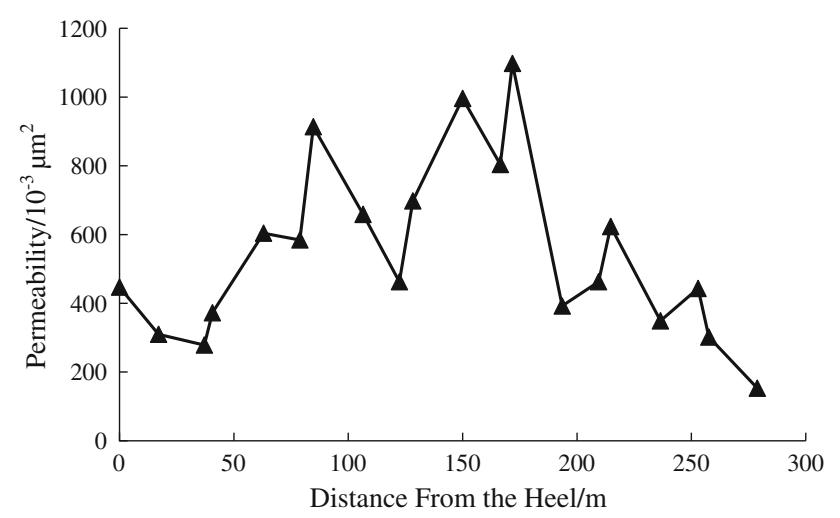

Fig. 8 Result of the well logging interpretation of the horizontal well's vertical permeability

recovery reaches about $21 \%$ and a line segment appears when oil recovery reaches about $26 \%$.

Compared with Fig. 6 and Table 2, it can be judged that the high permeability channel locates between Distribute 2 and Distribute 3, about in the middle of the wellbore. Figure 8 shows the vertical permeability along the wellbore interpreted by well logging data. We can see that the high permeability channel roughly locates between $100 \mathrm{~m}$ and $200 \mathrm{~m}$ from the heel. The result calculated is similar to the well $\log$ interpretation, and the method can be popularized.

\section{Conclusions}

1. A coupled model between two phase flow in the formation and variable mass flow in the horizontal wellbore has been built in this paper. By simulation, we can see that the distribution of vertical permeability along the wellbore plays an important part in the production data due to the presence of the wellbore pressure drop. As a result, the wellbore pressure drop cannot be ignored in the development of oil fields.

2. In the presence of a high permeability channel, there will be a line segment on the curve of cumulative watercut and oil recovery when oil recovery reaches some value. Affected by the high permeability channel, an inflexion will appear before the line segment, when the distance between the high permeability channel and the heel is greater than 0 .

3. A small distance between the high permeability channel and the heel of the wellbore contributes to a fast growth rate of watercut, an early appearance time of the inflexion and the line segment, and a serious effect of the high permeability channel on the watercut. The closer the distance between the high permeability channel and the toe of the horizontal well is, the clearer the inflexion will be.

4. The locations of high permeability channels can be judged through the oil recoveries when the inflexion and the line segment appear on the curve of cumulative watercut and oil recovery in semi-log coordinate, which can provide a theoretical basis for putting water plugging of horizontal well into effect.

Acknowledgments This work was financially supported by China National Science and Technology major project (2011ZX05009-00405) and National Natural Science Foundation of China (51104165).

Open Access This article is distributed under the terms of the Creative Commons Attribution License which permits any use, distribution, and reproduction in any medium, provided the original author(s) and the source are credited.

\section{References}

Bond AJ, Blount CG, Davies SN (1997) Novel approaches to profile modification in horizontal slotted liners at Prudhoe Bay, Alaska. SPE Annual Technical Conference and Exhibition, San Antonio, Texas, USA

Ehlers W, Bluhm J (2002) Porous media: theory, experiments, and numerical applications. Springer, New York

Erdal O, Rajagopal R (1989) Performance of horizontal wells subject to bottom water drive. SPE Reserv Eng 5:375-383

Li Y, Hu P, Feng J (2005) Background, current situation and trend of development for water shutoff in horizontal wells. J Jianghan Petrol 27:757-760

Liu C (1992) Critical rate of horizontal well for water crest. In: Proceedings of Fifth Asian Cong of Fluid Mechanics, Korea

Liu X, Jiang Z (1998) The model coupling fluid flow in reservoir with flow in the horizontal wellbore. SPE International Conference on Horizontal Well Technology, Calgary

Recham R, Osisanya SO, Touami M (2000) Effects of water coning on the performance of vertical and horizontal wells: a reservoir simulation study of hassi R' mel Field, Algeria. SPE/CIM International Conference on Horizontal Well Technology, Calgary, Alberta, Canada 
Sarabia J, Castillo E, Slottje DJ (1999) An ordered family of Lorenz curves. J Econ 91:43-60

Wibowo W, Permadi P, Mardisewojo P (2004) Behavior of water creasting and production performance of horizontal well in bottom water drive reservoir: a scaled model study. SPE Asia Pacific Conference on Integrated Modeling for Asset Management, Kuala Lumpur

Zaitoun A, Kohler N, Bossie-Codreanu D et al (1999) Water shutoff by relative permeability modifiers: lessons from several field applications. SPE Annual Technical Conference and Exhibition, Houston
Zhang J, Lei G, Zhang Y (2004) Fluid mechanics in porous medium in hydrocarbon reservoir. China University of Petroleum Press, Dongying

Zhou M, Zhao J, Pu W (2010) Preparation of a novel superior strength plugging agent resistant to heat and salt. J China Univ Petrol 34:61-66

Zhou W, Zhang S, Yu L (2011) The integrated technology of water detection, shutoff and regulating separate layer production in the oil recovery process. Nigeria Annual International Conference and Exhibition, Abuja 